\title{
A New Pandemic Coronavirus COVID-19 Evolutionary Relation, Transmission, Infectivity and Immunity
}

\author{
Afrah M. H. Salman \\ Department of Toxicology and Pharmacology, College of Pharmacy, Mustansiriyah University, Baghdad, Iraq.
}

\begin{tabular}{ll}
\hline \multicolumn{1}{c}{ Article's Information } & \multicolumn{1}{c}{ Abstract } \\
\hline Received: & The currently COVID-19 virus appeared in China in the beginning at December \\
07.10 .2020 & 2019, infected more than thousands of humans, by causing a severe respiratory \\
Accepted: & disease (like pneumonia), in severe cases lead to death. Rapidly spread all over \\
10.01 .2021 & the world and cause a pandemic as announced by the world health organization \\
Published: & (WHO), this virus showed a close evolutionary relation to other type of \\
23.04 .2021 & coronavirus, the sever acute respiratory syndrome coronavirus SARS-CoV, which \\
\hline Keywords: & is responsible for the endemic that appeared in 2002-2003. In this review it was \\
COVID-19 & been focused on the causes of the pandemic as well as study the results of the \\
Spike S protein & latest research in connection with the previous publications and the role of \\
ACE2 & molecular genetic analysis study of the viral RNA to get more knowledge about \\
Receptor binding domain & the evolutionary relation, infectivity and immunity. \\
Betacoronavirus &
\end{tabular}

DOI: 10.22401/ANJS.00.5.01

Corresponding author: afrahbassil@uomustansiriyah.edu.iq

\section{Introduction}

Since the end of the last year (2019) and so far, many world countries are attacked by a viral infection that initially diagnosed as pneumonia [1]. After one month of the outbreak triggered in Wuhan (a city in China) [2] it is considered as a pandemic, which is caused by a virus named COVID-19 according to the finding of studies on the genetic material isolate from chines patients [3]. All countries are still struggling with the quick spread among humans and the number of infected people is exponential increased with high number of deaths by the lung frailer as a consequence of the infection by this virus [2].

The main target of this review is to shed light on the reasons for the spread of the COVID-19 to be a pandemic and to understand the way the virus takes to invade the human body cells and its evolutionary relationship with other types of coronaviruses including sever acute respiratory syndrome coronavirus SARS-CoV, which is responsible for the endemic appears in 2002-2003, as well as to MERS, endemic in the Middle East [4]. Furthermore, in term of immunization the current review shade light on the evidences that promising or not to give protection against this pandemic.

\section{Spike Protein and its Role in the Virulence of COVID-19}

The COVID-19 is an outbreak pandemic currently appeared in China in the beginning of December 2019, infected more than thousands of humans around the world and causes a severe respiratory disease (like pneumonia), it is classified as RNA virus particle belong to the Betacoronavirus, human is the host when first isolated [5]. Coronavirus particle mainly composed of four proteins spike $S$, membrane $M$, envelope $\mathrm{E}$ and nucleocapsid N. lots of studies were conducted to understand the function of each structural protein and its relation with the coronavirus assembly, virulence and infectivity.

The previous studies were conducted to reveal the role and the structure of spike S [6] as well as M protein, they were all failed to give a clear image for the structure and assembly of these proteins, the main problem for identifying such characteristic was the using of cryo-EM which is lack of unlimited resolution [7]. Later publication performed by Newman et al. (2011) [8] gave a clear images for M protein and its essential role for giving the virus its specific shape and size using both cryo-EM and cryo-electrom tomography. This study showed that the physical characteristic of the $\mathrm{M}$ protein is highly influenced the density of spik proteins. And also showed that the M protein interaction with other types of proteins such as $\mathrm{N}$ and $\mathrm{S}$ is highly participating in the virus size regulation which all helps for the assembly to be a complete Coronavirus particle [8].

Other study showed the importance of spike glycoprotein $\mathrm{S}$ in the virulence of coronavirus, its molecular weight $180 \mathrm{kDa}$ and consists of two subunits, and act as a key for entering human cells $[9,10]$, which is compatible with a current study conducted by Ou et al. (2020) [11], detecting the important of the $\mathrm{S}$ domain for infectivity, after 


\title{
Al-Nahrain Journal of Science
}

\author{
Special Issue: COVID-19, April 2021, pp. 1-5
}

antibody neutralization, and then act as a receptor binding domain (RBD).

\section{Evolutionary Relation and Infectivity}

Nucleic acid alignment study by Wu et al (2020) [12], was performed to understand the evolutionary relation of the current pandemic causative virus (COVID-19) with other coronaviruses, the RNA analysis experiments of the extracted RNA genome (from patient) of COVID-19 showed a high percentage of identity with bat SARS-like coronavirus (COV) isolate (in China), and bat SLCoVZC45 virus, accession number MG772933 of GenBank. The alignment sequence was performed for the viral RNA (COVID-19) regarding to both SARS-CoV Tor2, and bat-SL-CoVZ45 to facilitate the genes order of the viral genome. Furthermore, the outcome of Wu et al. (2020) [12] study has emphasis that this virus has an evolutionary relation with the SARS-CoV. In this review a sequence analysis was performed to get evidence for the evolutionary relation between the current pandemic causative agent virus and coronaviruses causing the SARS and MERS endemics in 2002-2003 and 2004. Briefly, the sequence of the spike S protein of two isolate of each virus including: COVID-19 (Severe acute respiratory syndrome coronavirus 2), SARSCoV1 (Severe acute respiratory syndrome-related coronavirus), MERS coronavirus (Middle East respiratory syndrome-related coronavirus, and Bat coronavirus, from NCBI (National Center for Biotechnology Information) of the National Library of Medicine, were blast and alignment to see the percentage of the compatibility between the selected $\mathrm{S}$ protein sequences. The reason for choosing $\mathrm{S}$ protein, because it is containing the genetic information coding S1 domain, this domain is the key for receptor binding to ACE2 human cell as confirmed in previous studies $[13,14,9,10]$. The results showed that a high percentage of identity between COVID-19 and SARSCoV1 is $75.9 \%$. The phylogenetic tree revealed the presence of variable evolutionary relation between the selected coronavirus; however, it showed a low diversity between COVID-19 and SARS-CoV1 (see Figure 1). These all conclude the presence of a close evolutionary relation of the current pandemic causative agent and SARS-CoV.

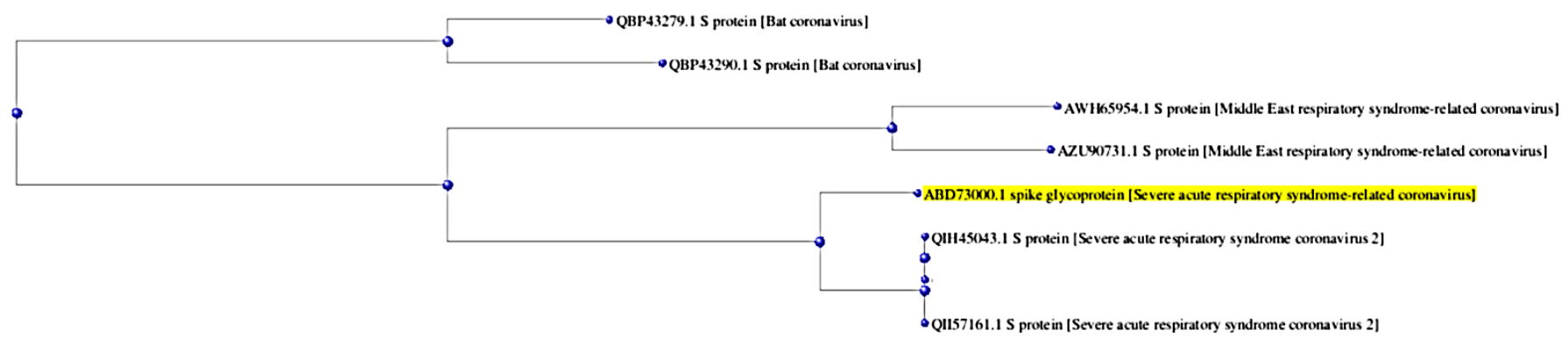

Figure 1. Phylogenetic tree according to the spike S protein of SARS-CoV. Sequences of Sprotein of the selected coronavirus isolates are from NCBI (National Center for Biotechnology Information) of the National Library of Medicine. Alignment performed using NCBI - BLAST.

Zhou et al., (2020) [15] infectivity studies showed that the entry receptor for COVID-19 in human, bats, civets and pigs, is ACE2, sharing this characteristic with SARS-CoV. However it couldn't infect mice because of lacking this receptor in mice.

The finding of the work done by Wu et al (2020) [12] showed that the spike protein of the COVID-19 particularly the receptor-binding domain (RBD) is comparable to that in both SARS-CoVs and SARS-like CoVs (see Figure 2) and the percentage of identity was approximately $74 \%$ and $77 \%$ respectively. Furthermore, they are all sharing the same human cell entry receptor for invasion (ACE2). recent study using a docking analysis indicate that $S$ protein have the ability to bind not only ACE2 but also CD26, and displayed an image of the interface of COVID-19 with CD26 [16], a previous study also showed that $\mathrm{S}$ protein of Bat-CoV binding to several residues of CD26 [17], and this similarity in invasion behavior also indicate that they could belong to the same genus. 


\title{
Al-Nahrain Journal of Science
}

\author{
Special Issue: COVID-19, April 2021, pp. 1-5
}

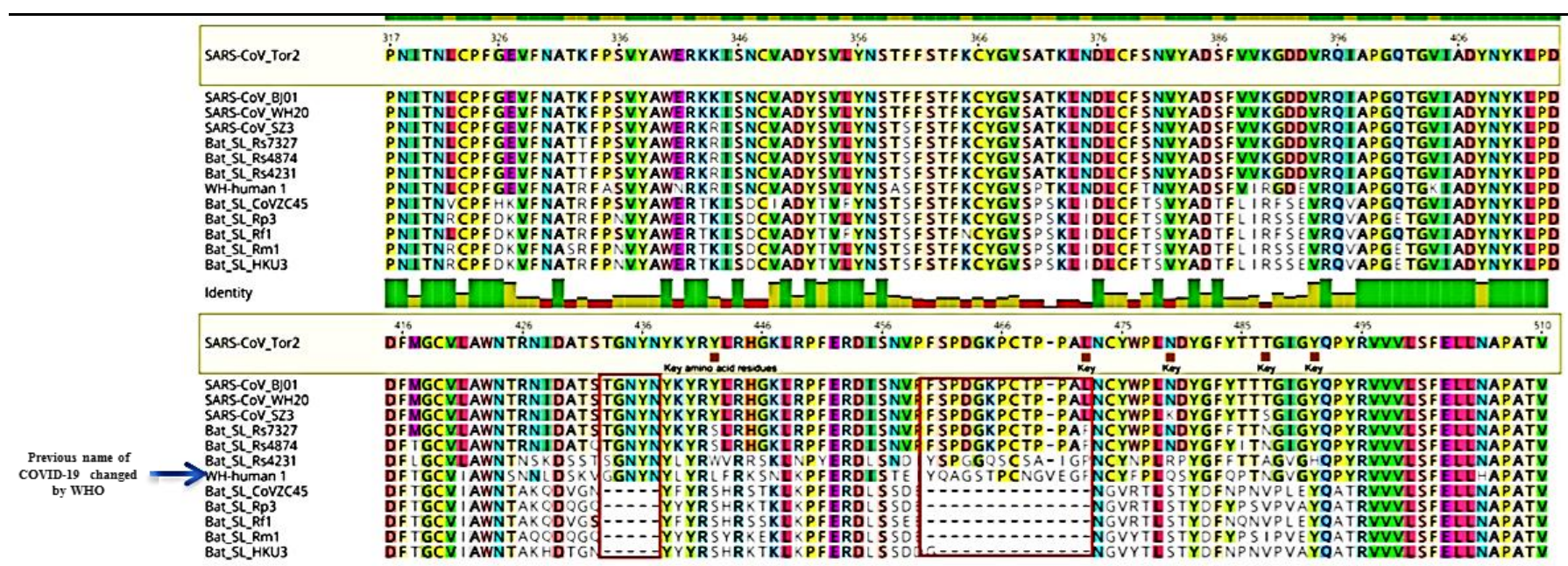

Figure 2. Alignment of Receptor Binding Domain, amino acid sequences for COVID-19, SARS-CoVs, and bat SARS-like CoVs. Key motifs participate in the binding with ACE2 of human cells are indicated by an orange square [12].

\section{Animals that are Expected to be the Source of the Pandemic}

To understand and get information about the host of the coronavirus, many studies were performed; one of these was done by Song et al. (2005) [18] to investigate the source of the pandemic outbreak of infection, caused by the SARSCoVs, in 2003 triggers in Korea. Their finding showed a high similarity percentage of the virus genetic materials isolated from both civet and human. The highly presence of civets in the market and restaurant during the pandemic time [19], and the observation of other study to investigate the source of infection, which revealed the relation of the infection of both customers and workers with the civets (positively test for SARS-CoV) that housed in the restaurant [20] these together reach to the suggestion that civets act as a host for the SARS-CoV transmitted to the human and causing a severe respiratory syndrome.

It is also known through previous research that bats are the main host of coronavirus causing diseases for humans. These studies, regarding the pandemic of coronavirus in 2003 , indicated that the bats are the host animal for SARSCoVs, depending on the results of polymerase chain reaction and serological study, and showed the presence of the antibody to that virus as well as the presence of the virus genome in the specimen taken from horseshoe bats [21, 22]. In the current pandemic, the first infection recorded in Wuhan 2019 was for a man working in the market selling wild animals and seafood, and no bats exist. However, the amino acid analysis study of the COVID-19 in this patient shows strong evidence that the virus is belong to the genus Betacoronavirus.

\section{Dose the Immunity Against One Genera of Coronavirus Give a Protection from others? and Does COVID-19 Vaccine give Protection / Reduce Transmission?}

Although the molecular studies showed a high percentage similarity between COVID-19 and other type of coronavirus like SARS-CoVs and SARS-like CoVs, particularly the infectivity entry domain, the research showed that the immunization against SARS-CoVs after recovery possibly will not prevent from infection with COVID-19, this suggestion is based on the observation of the presence of moderate cross-neutralization in the serum between these two viruses [11].However, The interaction of the COVID-19 with CD26 of the human cells, which is mentioned above, could inspire scientists to find a new therapeutics to prevent such infectivity pathway.

The subsequent experimental study on COVID-19 immunity and vaccine revealed that the necessity of immunization about quarter to half population is essential to defeat and reduce the virus transmission [23, 24, 25]. The finding of studies showed that the immunization through antibody neutralization insure the protection from the subsequent infection with COVID-19 [26]. However, the current research on other type of immunization including the cytotoxicity of cells depending on antibody is uncertain [27]. Although the work in progress for the assessing the affectivity of COVID-19 vaccine in different country, Peiris and Leung (2020) couldn't accept the idea of the vaccine is going to decrease the rate of infection spreading. Furthermore, the experiments on COVID-19 vaccine are still in phase three trials [28] and the ability of this vaccines for reducing the transmission rate is still not evaluated, and it is not expected to be a final elucidation. However, if the vaccination results appeared to be effective and highly reduce the death rate, it would be recommended, even it has effect on the immunity of population and transmission [27]. Because there is no specific medication for COVID-19 treatment so far, it is very important to follow safety guidelines including wearing face mask and washing hands regularly in addition to the social distance [29, 30, 31].

\section{Conclusion}

The global finding of the scientists was all beneficial towards displaying their efforts and experimental studies 


\section{Al-Nahrain Journal of Science}

Special Issue: COVID-19, April 2021, pp. 1-5

which it is possible to open new horizons for other scientists, and use the indicated features of the novel COVID-19, to develop and find treatments that may alleviate the severity of symptoms of the virus or working to produce a vaccine to impede it to cause infection. Since the work on vaccines is still ongoing and experiments are incomplete, and there is no effective specialized treatment against the virus, the safety guidelines which were recommended by the World Health Organization should not be neglect and the health policies should be updated according to the number of deaths and infections in each specific area.

\section{References}

[1] Yang Q. X.; Zhao T. H.; Sun C. Z.; Wu L. M.; Dai Q.; Wang S. D. and Tian H., "New thinking in the treatment of 2019 novel coronavirus pneumonia", Complementary Therapies in Clinical Practice, 39, 101131, 2020.

[2] Wang K.; Qiu Z.; Liu J.; Fan T.; Liu C.; Tian P.; Wang, Y.; Ni Z.; Zhang S.; Luo J. and Liu D., "Analysis of the clinical characteristics of 77 COVID-19 deaths", Scientific reports, 10(1), .1-11, 2020.

[3] Kang L.; Li Y.; Hu S.; Chen M.; Yang C.; Yang B. X.; Wang Y.; Hu J.; Lai J.; Ma X. and Chen J., "The mental health of medical workers in Wuhan, China dealing with the 2019 novel coronavirus", The Lancet Psychiatry, 7(3), e14, 2020.

[4] Meo S. A.; Alhowikan A. M.; Al-Khlaiwi T.; Meo I. M.; Halepoto D. M.; Iqbal M.; Usmani A. M.; Hajjar W. and Ahmed N. Novel coronavirus 2019-nCoV: prevalence, biological and clinical characteristics comparison with SARS-CoV and MERS-CoV. Eur Rev Med Pharmacol Sci, 24(4), pp.2012-2019, 2020.

[5] Lu R.; Zhao X.; Li J.; Niu P.; Yang B.; Wu H.; Wang W.; Song H.; Huang B.; Zhu N. and Bi Y., "Genomic characterisation and epidemiology of 2019 novel coronavirus: implications for virus origins and receptor binding", The Lancet, 395(10224), 565-574, 2020.

[6] Neuman B. W.; Adair B.D.; Yoshioka C.; Quispe J. D.; Orca G.; Kuhn P.; Milligan R. A.; Yeager M. and Buchmeier M. J., "Supramolecular architecture of severe acute respiratory syndrome coronavirus revealed by electron cryomicroscopy", Journal of virology, 80(16), 7918-7928, 2006.

[7] Stewart A. and Grigorieff N., "Noise bias in the refinement of structures derived from single particles", Ultramicroscopy, 102(1), 67-84, 2004.

[8] Neuman B. W.; Kiss G.; Kunding A. H.; Bhella D.; Baksh M. F.; Connelly S.; Droese B.; Klaus J. P.; Makino S.; Sawicki S. G. and Siddell S. G., "A structural analysis of $\mathrm{M}$ protein in coronavirus assembly and morphology", Journal of structural biology, 174(1), 11-22, 2011.

[9] Li W.; Moore M. J.; Vasilieva N.; Sui J.; Wong S. K.; Berne M. A.; Somasundaran M.; Sullivan J. L.; Luzuriaga K.; Greenough T. C. and Choe H., "Angiotensin-converting enzyme 2 is a functional receptor for the SARS coronavirus", Nature, 426(6965), 450-454, 2003.

[10] Bonavia A.; Zelus B. D.; Wentworth D. E.; Talbot P. J. and Holmes K. V., "Identification of a receptorbinding domain of the spike glycoprotein of human coronavirus HCoV-229E", Journal of Virology, 77(4), 2530-2538, 2003.

[11] Ou J.; Zhou Z.; Dai R.; Zhang J.; Lan W.; Zhao S.; Wu J.; Seto D.; Cui L.; Zhang G. and Zhang Q., "Emergence of RBD mutations in circulating SARSCoV-2 strains enhancing the structural stability and human ACE2 receptor affinity of the spike protein", bioRxiv, Jan 1, 2020.

[12] Wu F.; Zhao S.; Yu B.; Chen Y. M.; Wang W.; Song Z. G.; Hu Y.; Tao Z. W.; Tian J. H.; Pei Y. Y. and Yuan M. L., "A new coronavirus associated with human respiratory disease in China”, Nature, 579(7798), 265-269, 2020.

[13] Xu X.; Chen P.; Wang J.; Feng J.; Zhou H.; Li X.; Zhong W. and Hao P., "Evolution of the novel coronavirus from the ongoing Wuhan outbreak and modeling of its spike protein for risk of human transmission", Science China Life Sciences, 63(3), 457-460, 2020.

[14] Song W.; Gui M.; Wang X. and Xiang Y.; "Cryo-EM structure of the SARS coronavirus spike glycoprotein in complex with its host cell receptor ACE2", PLoS pathogens, 14(8), e1007236, 2018.

[15] Zhou P.; Yang X. L.; Wang X. G.; Hu B.; Zhang L.; Zhang W.; Si H. R.; Zhu Y.; Li B.; Huang C. L. and Chen H. D., "A pneumonia outbreak associated with a new coronavirus of probable bat origin", Nature, 579(7798), 270-273, 2020.

[16] Vankadari N. and Wilce J. A., "Emerging WuHan (COVID-19) coronavirus: glycan shield and structure prediction of spike glycoprotein and its interaction with human CD26", Emerging Microbes \& Infections, 9(1), 601-604, 2020.

[17] Wang Q.; Qi J.; Yuan Y.; Xuan Y.; Han P.; Wan Y.; Ji W.; Li Y.; Wu Y.; Wang J. and Iwamoto A., "Bat origins of MERS-CoV supported by bat coronavirus HKU4 usage of human receptor CD26", Cell host \& microbe, 16(3), 328-337, 2014.

[18] Song H. D.; Tu C. C.; Zhang G. W.; Wang S. Y.; Zheng K.; Lei L. C.; Chen Q. X.; Gao Y. W.; Zhou H. Q.; Xiang H. and Zheng H. J., "Cross-host evolution of severe acute respiratory syndrome coronavirus in palm civet and human", Proceedings of the National Academy of Sciences, 102(7), 2430-2435, 2005.

[19] Wang L. F.; Shi Z.; Zhang S.; Field H.; Daszak P. and Eaton B. T., "Review of bats and SARS", Emerging infectious diseases, 12(12), 1834, 2006.

[20] Wang M.; Yan M.; Xu H.; Liang W.; Kan B.; Zheng B.; et al., "SARS-CoV infection in a restaurant from palm civet", Emerg Infect Dis. 11, 1860-5, 2005.

[21] Li W.; Shi Z.; Yu M.; Ren W.; Smith C.; Epstein J. H.; et al., "Bats are natural reservoirs of SARS-like 


\section{Al-Nahrain Journal of Science}

Special Issue: COVID-19, April 2021, pp. 1-5

coronaviruses, "Science. 310:676-9 10.1126/science. 1118391, 2005.

[22] Lau S. K. P.; Woo P. C. Y.; Li K. S. M.; Huang Y.; Tsoi H. W.; Wong B. H. L.; et al., "Severe acute respiratory syndrome coronavirus-like virus in Chinese horseshoe bats", Proc Natl Acad Sci USA. 102:14040-5 10.1073/pnas.0506735102, 2005.

[23] Li Q.; Guan X.; Wu P.; Wang X.; Zhou L.; Tong Y.; Ren R.; Leung K. S.; Lau E. H.; Wong J. Y. and Xing X., "Early transmission dynamics in Wuhan, China, of novel coronavirus-infected pneumonia", New England Journal of Medicine, 2020.

[24] Adam D.; Wu P.; Wong J.; Lau E.; Tsang T.; Cauchemez S.; Leung G. and Cowling B., "Clustering and superspreading potential of severe acute respiratory syndrome coronavirus 2 (SARS-CoV-2) infections in Hong Kong", 2020.

[25] Gomes M. G. M.; Aguas R.; Corder R. M.; King J. G.; Langwig K. E.; Souto-Maior C.; Carneiro J.; Ferreira M. U. and Penha-Goncalves C., "Individual variation in susceptibility or exposure to SARS-CoV-2 lowers the herd immunity threshold", medRxiv, 2020.

[26] Addetia A.; Crawford K. H.; Dingens A.; Zhu H.; Roychoudhury P.; Huang M. L.; Jerome K. R.; Bloom J. D. and Greninger A. L., "Neutralizing antibodies correlate with protection from SARS-CoV-2 in humans during a fishery vessel outbreak with a high attack rate", Journal of Clinical Microbiology, 58(11), 2020.

[27] Peiris M. and Leung G. M., "What can we expect from first-generation COVID-19 vaccines?", The Lancet, 396(10261), 1467-1469, 2020.

[28] WHO Draft landscape of COVID-19 candidate vaccines. Sept 9, 2020.

[29] Alsayed R.; Kadhom M.; Yousif E. and Sabir D. K., "An Epidemiological Characteristic of the COVID-19 Among Children", Letters in Applied NanoBioScience, 9(3), 1156-1164, 2020.

[30] Hadi A. G.; Kadhom M.; Hairunisa N.; Yousif E. and Mohammed S. A., "A review on COVID-19: origin, spread, symptoms, treatment, and prevention", Biointerface Research in Applied Chemistry, 10, 7234-7242, 2020.

[31] Hadi A. G.; Kadhom M.; Yousif E. and Hairunisa N., "In COVID-19 time, how to protect myself and others? A review", Jurnal Biomedika dan Kesehatan, 3(3), 2020. 